\title{
The Augment of the Stability in Locking Compression Plate with Intramedullary Fibular Allograft for Proximal Humerus Fractures in Elderly People
}

\author{
Hua Chen, ${ }^{1}$ Peng Yin $\mathbb{D}^{2},{ }^{2}$ Song Wang, ${ }^{1,3}$ Jiantao Li $\left(\mathbb{D},{ }^{1}\right.$ Lihai Zhang, ${ }^{1}$ Kamran Khan $\mathbb{D}$, \\ Licheng Zhang $\mathbb{\oplus}{ }^{1}$ and Peifu Tang $\mathbb{1}^{1}$ \\ ${ }^{1}$ Department of Orthopedics, Chinese PLA General Hospital, No. 28 Fuxin Road, Beijing 100853, China \\ ${ }^{2}$ Department of Orthopedics, Beijing Chaoyang Hospital, Capital Medical University, No. 8 GongTiNanLu, Beijing 100020, China \\ ${ }^{3}$ Medical College, Nankai University, No. 94 Weijin Road, Tianjin 300071, China \\ ${ }^{4}$ Department of Orthopedic Surgery, Massachusetts General Hospital and Harvard Medical School, Boston, MA, USA
}

Correspondence should be addressed to Licheng Zhang; zhanglcheng218@126.com and Peifu Tang; pftang301@163.com

Received 6 June 2018; Accepted 12 August 2018; Published 16 September 2018

Academic Editor: Despina Deligianni

Copyright ( 2018 Hua Chen et al. This is an open access article distributed under the Creative Commons Attribution License, which permits unrestricted use, distribution, and reproduction in any medium, provided the original work is properly cited.

\begin{abstract}
Objective. The objective of this study was to compare the clinical outcomes and complications between the locking compression plate (LCP) and LCP with fibular allograft in the treatment of patients with displaced proximal humerus fracture (PHF) in elderly people. Material and Methods. Between January 2010 and December 2013, a total of 97 elderly patients with displaced PHF were treated by LCP or LCP with fibular allograft, and finally 89 patients were included in our study. All the patients were divided into Group I (patients treated by LCP) and Group II (patients treated by LCP with fibular allograft). Function results were assessed by the disability of the arm, shoulder, and hand (DASH) score and Constant-Murley score (CMS), and complications were also recorded in each group. Results. The average follow-up was 35.2 months (range, 24-48 months) in Group I and 33.5 months (range, 24-48 months) in Group II. DASH in patients of Group I was significantly higher than that in patients in Group II and patients of Group I had CMS scores significantly lower than patients in Group II $(\mathrm{P}<0.05)$. The rates of varus malunion, screw perforation, and loss of reduction $>5 \mathrm{~mm}$ were significantly higher in Group I than in Group II $(\mathrm{P}<0.05)$. Conclusions. The present results showed that that patients treated by LCP with fibular allograft had a better functional outcome and a lower complication rate compared to patients treated by LCP alone. Suitable void filler in the proximal humerus for supporting the head fragment, medial cortical bone, and greater tuberosity might play a key role in reducing the incidence of the complications in elderly patients, especially with osteoporosis.
\end{abstract}

\section{Introduction}

Fractures of the proximal humerus account for $4 \%-5 \%$ of the whole body bone fractures $[1,2]$, and proximal humerus fracture (PHF) is the third common injury among the older people [3]. It has been reported that the incidence of PHF is increasing, especially in the older people $[4,5]$. The majority of patients with stable or minimally displaced PHF could be treated conservatively $[6,7]$, but displaced PHF may require a surgical treatment in order to achieve fracture stability and allow for early motion [8]. Operative management of PHF still remains challenging for orthopedic surgeons in the world [8-11].
Various surgical techniques have been described for the unstable PHF, including tension banding [12, 13], intramedullary nailing [14-16], non-locking and locking plating [17-19], and shoulder hemiarthroplasty (HA) [20, 21]. Until now, there is still different consensus about the best treatment for PHF $[22,23]$. Biomechanical data and clinical outcomes demonstrated that locking plating for displaced PHF is a promising treatment compared to other methods [24-28]. However, high complication rates of up to $49 \%$ in PHF patients by using locking plating method have been reported, and the most two common complications are varus malunion and screw perforation $[9,10,29]$. Therefore, many efforts have been made in order to overcome these 
problems, such as medial support screws [11, 30], cement augmentation [23, 31], additional medial plate [32], and bone autograft [33]. These treatments have partly decreased the complication rates, but meanwhile caused other problems, including humeral head necrosis [11], cement-related heat injuries [34], neurovascular injuries [32], and donor-site morbidity $[35,36]$.

Elderly people usually are accompanied by osteoporosis, and osteoporosis increases the difficulty of treating displaced PHF due to low bone mineral density (BMD) [37]. One study showed that the osteoporotic PHF was similar to the breakage of eggshell, and the contents in humeral head were nearly empty [38]. Therefore, effective augment of bone-to-implant construct is very critical. Biomechanical data demonstrated that a fibular allograft could increase the maximal failure loads of LCP fixation system and decrease the rate of varus collapse [37]. Additionally, fibular allograft could provide adequate bone stock, obtain easily, and avoid the donor-site morbidity [39]. In our pervious study [40], we adopted the technique of locking compression plate (LCP) with fibular allograft for the treatment of elderly four-part PHF, and the clinical results were favorable.

Although there are four biomechanical comparison studies on LCP and LCP with fibular allograft in PHF models [41-44], to our best knowledge, no comparative clinical study between LCP and LCP with fibular allograft for the treatment of PHF has been performed. Therefore, the aim of the present study was to compare the outcomes and complications of LCP and LCP with fibular allograft in elderly displaced PHF.

\section{Material and Methods}

Between January 2010 and December 2013, 97 patients with displaced PHF were operated by LCP or LCP with fibular allograft at our hospital. The inclusion criteria were (1) patients of age of 60 years or more, (2) acute unilateral closed three-part or four-part PHF, and (3) fracture fragments displaced more than $1 \mathrm{~cm}$ or angulated more than $45^{\circ}$. The exclusion criteria were (1) a history of shoulder surgery or chronic nonunion, (2) pathological or open fractures, and (3) complications of serious nervous or vascular injury. Finally, 89 patients were recruited in our study. The study was approved by our Institutional Review Board and written consent was obtained from all the subjects prior to participation in this study.

Appropriate clinical and radiological assessments were carried out for every patient before operation, and all patients received $1.5 \mathrm{~g}$ cefuroxime preoperatively. All fractures were classified according to the Neer classification system [45]. All patients were then divided into two groups in line with different surgical techniques, and the patients operated by LCP alone were regarded as Group I, and the patients operated by LCP with fibular allograft were viewed as Group II.

In Group I, surgeries were performed through a standard deltopectoral approach [46], and a LCP ((Synthes, Switzerland) was placed in the fracture site after surgical reduction. At least 5 screws were fixed in the humeral head and the place of the screw tip was confirmed by an image

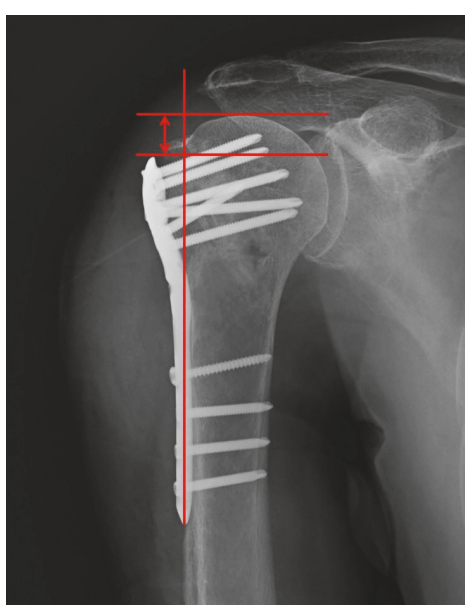

FIGURE 1: The illustration of the measurement of the height between the superior edge of the humeral head and the top edge of the proximal plate.

intensifier during the operation. After meticulous irrigation, the incision was closed with a negative suction drain. In Group II, all the procedures were performed as our previous study [40]. In brief, operations were conducted through a standard deltopectoral approach, and the reduction of the humeral head and shaft was completed by laminar spreader under fluoroscopy. And then the fibular allograft, including fibular shaft or anatomical allograft, was inserted into the intramedullary canal from the lateral window of tuberosity fracture sites. In order to prevent the humeral head from varus displacement and deformation, the fibular allograft was pushed onto the medial calcar. After that, the greater tuberosity fragment was reduced and fixed, and then a LCP (Synthes, Switzerland) was fixed in the fracture sites. The locations of plate and screws were confirmed by fluoroscopy. If the fixation was satisfied, careful irrigation would be performed, and finally the incision was closed in layers with a negative suction drain.

The "humeral head height" between the superior edge of the humeral head and the top edge of the proximal plate was measured on true anteroposterior (AP) radiographs of the shoulder, postoperatively and at 3-month follow-up, as Gardner's previous description [30] (Figure 1). A decrease of the height was interpreted as a loss of reduction. The humeral neck-shaft angle was measured as Agudelo's description [8] (Figure 2). In brief, a line was drawn from the superior to the inferior border of the articular surface, and then another line perpendicular to the previous line was drawn through the center of the humeral head. The angle between the perpendicular line and the line bisecting the humeral shaft was described as the humeral neck-shaft angle. After operation, restoration of the humeral neck-shaft angle up to $120^{\circ}-150^{\circ}$ was defined as anatomical reduction, acceptable reduction was defined as being between $110^{\circ}$ and $120^{\circ}$, and malreduction was defined as being $>150^{\circ}$ or $<110^{\circ}$ [47].

Patients were immobilized in a sling postoperatively, and they begin to perform passive mobilization and pendulum exercises immediately. In addition, physiotherapy was carried 
TABLE 1: Demographic characteristics data for patients included in this study.

\begin{tabular}{lccc}
\hline Characteristic & Group I (n=42) & Group II (n=47) & P-value \\
\hline Average age (year) & 69.12 & 68.60 & 0.524 \\
Sex distribution (male : female) & $15: 27$ & $12: 35$ & 0.359 \\
Dominant arm involvement & $14: 28$ & $18: 29$ & 0.664 \\
The mechanism of injury (F: TA) & $37: 5$ & $40: 7$ & -2.52 \\
Dual mineral absorptiometry & -3.0 & $12: 35$ & 22 \\
Classification of Neer (3 part : 4 part) & $10: 32$ & 6.74 & 0.680 \\
Medial comminution & 18 & 232.77 & 130.15 \\
The mean time from injury to surgery (day) & 6.60 & 45 & 0.851 \\
Intraoperative bleeding volume (ml) & 219.52 & 1 & 0.708 \\
Neck-shaft angle (degree) & 128.71 & 34 & 0.332 \\
Anatomical reduction & 7 & 1 & 0.450 \\
Acceptable reduction & 1 & & 0.056 \\
Malreduction & &
\end{tabular}

F: fall, TA: traffic accident.

out to all patients and gradually ceased around 3 weeks. The outcomes of operation based on patients' subjective rating were classified into four types as follows: excellent, good, fair, and poor. Function results were assessed by the disability of the arm, shoulder, and hand (DASH) score and ConstantMurley score (CMS). We employed dual-emission X-ray absorptiometry (DXA) to evaluate bone mineral density (BMD) for every patient. Radiographs, including true AP, axillary, and scapular $Y$ views, were reviewed postoperatively and at 1 month, 2 months, 3 months, 6 months, 12 months, 24 months, and 48 months following operation. Complications, such as varus malunion, screw perforation, infection, and humeral head necrosis, were recorded during the follow-up. The data were analyzed by SPSS 15.0 software with independent $t$-test in continuous variables and chi-square and Fisher's exact test in nominal data. A statistically significant difference was determined when $\mathrm{p}<0.05$.

\section{Results}

42 patients with LCP and 47 patients with LCP and fibular allograft were included in Group I and Group II, respectively. In Group I, there were 15 males and 27 females, with an average of 69.12 years (range, 60-85 years). All the injured arms were dominant. 18 patients suffered from medial comminution. The mean angle of the postoperative humeral neck-shaft was 128.71 degrees. According to the postoperative humeral neck-shaft angle, there were 34 patients with anatomical reduction, 7 patients with acceptable reduction, and 1 patient with malreduciton. In Group II, there were 12 males and 35 females, with an average of 68.60 years (range, 60-83 years). All the injured arms were dominant. 22 patients suffered from medial comminution. The mean angle of the postoperative humeral neck-shaft was 130.15 degrees. According to the postoperative humeral neck-shaft angle, there were 45 patients with anatomical reduction, 1 patient with acceptable reduction, and 1 patient with malreduciton. More demographic characteristics data of the two group were listed Table 1 . There was no statistical significance between

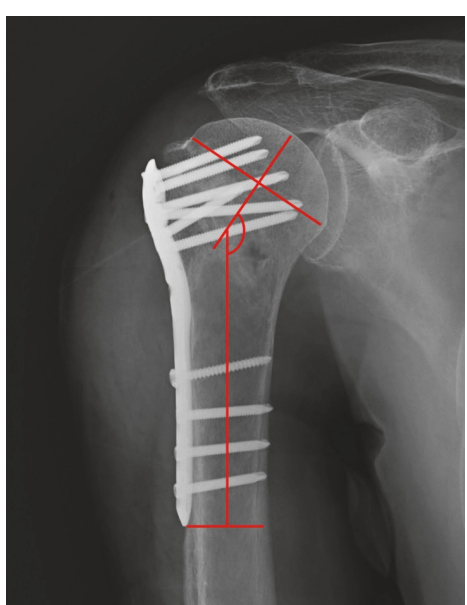

FIGURE 2: The illustration of the measurement of the humeral neckshaft angle.

the two groups in the demographic characteristics $(\mathrm{P}>0.05$, Table 1).

The average follow-up was 35.2 months (range, 24-48 months) in Group I and 33.5 months (range, 24-48 months) in Group II. The rates of varus malunion, screw perforation, and loss of reduction $>5 \mathrm{~mm}$ were significantly higher in Group I than in Group II $(\mathrm{P}<0.05)$. There was no statistical significance between the two groups in the rates of avascular necrosis $(\mathrm{P}>0.05)$. In general, the group with LCP and fibular allograft had 2 varus malunion and 1 screw perforation in comparison to a large number in the LCP alone group. The rate of total complications was significantly higher in Group I than in Group II $(\mathrm{P}<0.05)$. More details were listed in Table 2.

$\mathrm{DASH}$ in patients of Group I in was significantly higher than patients in Group II and CMS scores of patients of Group I were significantly lower than those of patients in Group II $(\mathrm{P}<0.05)$. Furthermore, our clinical results rated by the patients' subjective evaluation showed that excellent and good function in Group II was significantly higher than that 
TABLE 2: Functional outcomes and complications of patients in two groups.

\begin{tabular}{lccr}
\hline Variable & Group I $(\mathrm{n}=42)$ & Group II $(\mathrm{n}=47)$ & P-value \\
\hline$>5$ mm loss of reduction & 9 & 2 & 0.022 \\
Functional outcomes & & & 36.17 \\
DASH & 49.00 & 74.38 & 0.001 \\
CMS & 70.29 & & 0.020 \\
Complications & & 2 & 0.042 \\
Varus malunion & 8 & 1 & 0.049 \\
Screw perforation & 6 & 5 & 0.717 \\
Avascular necrosis & 3 & 8 & 0.018 \\
Total complications & 17 & & \\
\hline
\end{tabular}

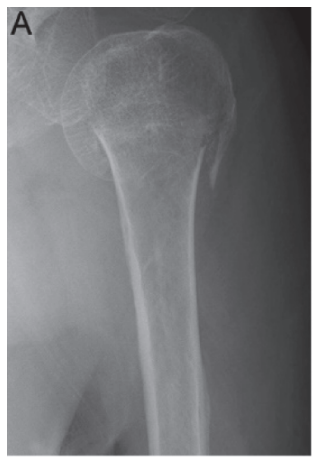

(a)

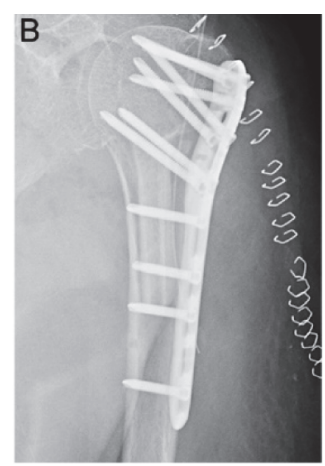

(b)

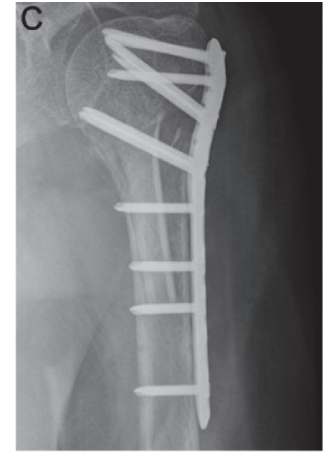

(c)

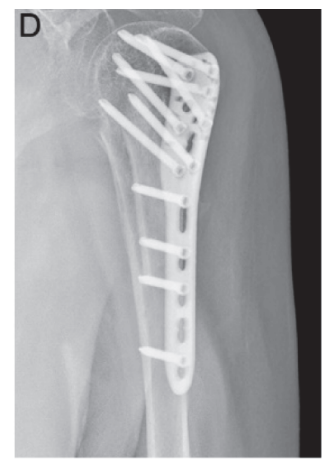

(d)

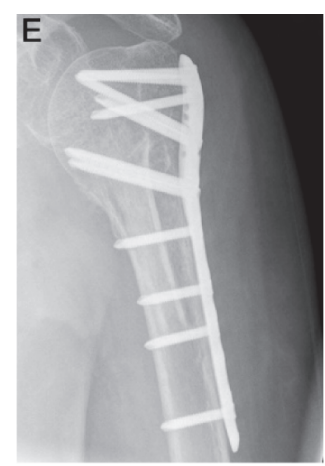

(e)

FIGURE 3: Radiograph of an 80-year-old woman with 4-part PHF treated by locking compression plate with intramedullary fibular allograft. (a) Preoperative X-ray film; (b) postoperative X-ray film; (c) X-ray film 3 months after operation; (d) X-ray film 6 months after operation; (e) $\mathrm{X}$-ray film 18 months after operation.

TABLE 3: Patients' subjective evaluation of clinical results at 24 months.

\begin{tabular}{lccccc}
\hline Groups & Excellent & Good & Fair & Poor & P-value \\
\hline Group I & 23 & 15 & 3 & 1 & 0.001 \\
Group II & 43 & 4 & - & - & \\
\hline
\end{tabular}

in Group $\mathrm{I}(\mathrm{P}<0.05)$ (Figures 3 and 4). More details were listed in Tables 2 and 3.

\section{Discussion}

This is a retrospective comparative clinical study of LCP alone and LCP with fibular allograft in the treatment of elderly displaced PHF. The present study showed that patients treated by LCP with fibular allograft had a better functional outcome and a lower complication rate in comparison to patients treated by LCP alone. Therefore, fibular allograft played an important role in the treatment of elderly displaced PHF, especially in the patients with osteoporosis. In our clinical experience, there are four major effects of fibular allograft as follows (Figure 5): (1) fibular allograft as volumetric filling in the bone void could prevent the humeral head to retreat after LCP fixation; (2) fibular allograft could provide enough medial stability and thus avoid the humeral head varus; (3) fibular allograft, especially in anatomical type, could provide the support for greater tuberosity, which is good for the restoration of the shape of greater tuberosity so as to improve the abduction function of shoulder; (4) fibular allograft would not disturb the blood supply of the humeral head, and, on the contrary, it provides a stable surface that could allow osteogenic tissue across the fracture site and then accelerate the fracture healing.

Although the optimal surgical management of elderly displaced PHF has not been determined, most of surgeons believed that LCP is a promising treatment for PHF. There are several advantages for LCP system of the proximal humerus, such as anatomic design, divergent angulated configuration of locking screws, and high rotational and angular stability [48]. However, a high complication rate has been reported in the treatment of PHF by using LCP alone [9]. Therefore, researchers began to realize the importance of medial support and BMD [11, 30, 48-50]. They found that lack of medial support and a low BMD were associated with a higher risk of loss of reduction and a poor clinical result after LCP fixation. Gardner et al. were the first to describe the importance of medial support in the treatment of $\mathrm{PHF}$ by LCP [30]. They conducted that medial support screws played a key role in LCP fixation of displaced PHF, but a biomechanical study showed the addition of medial support screws had no effect on the stiffness of the medial cortex 


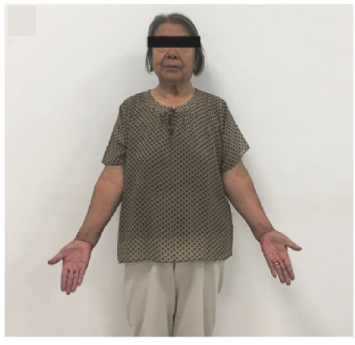

(a)

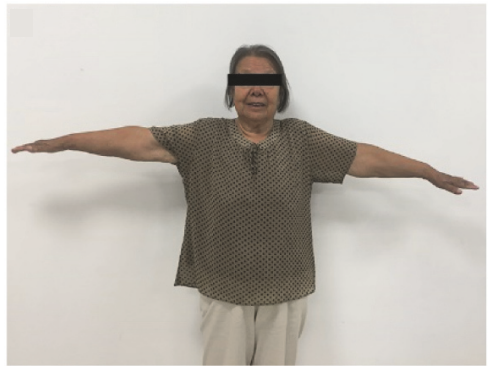

(e)

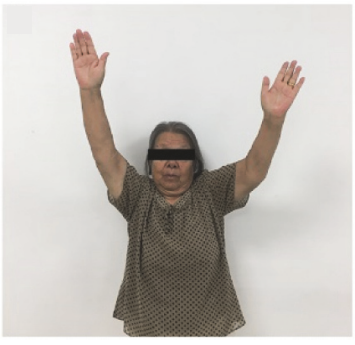

(b)

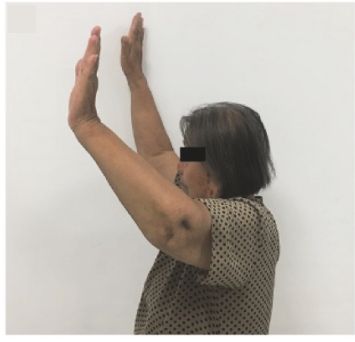

(c)

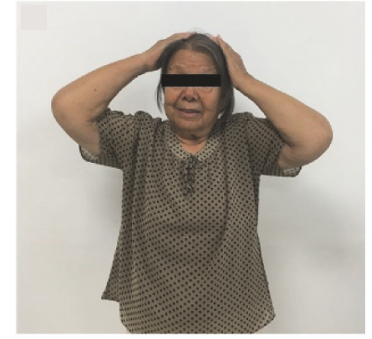

(d)

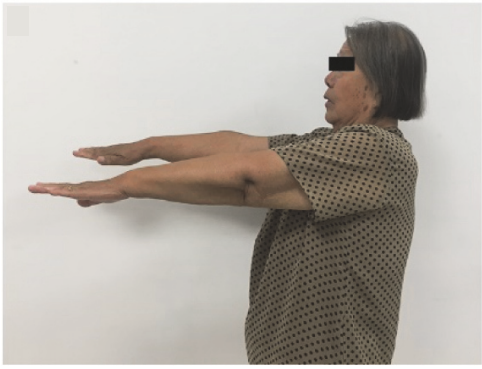

(f)

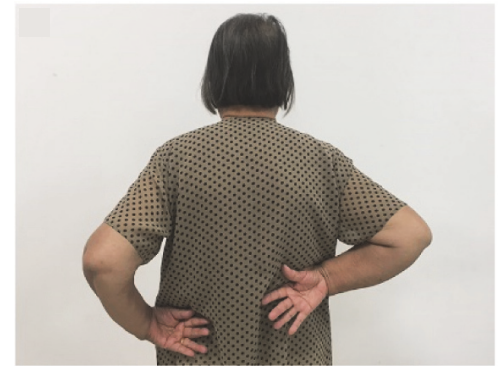

(g)

FIGURE 4: Function recovery of the patient in Figure 3 at follow-up period.

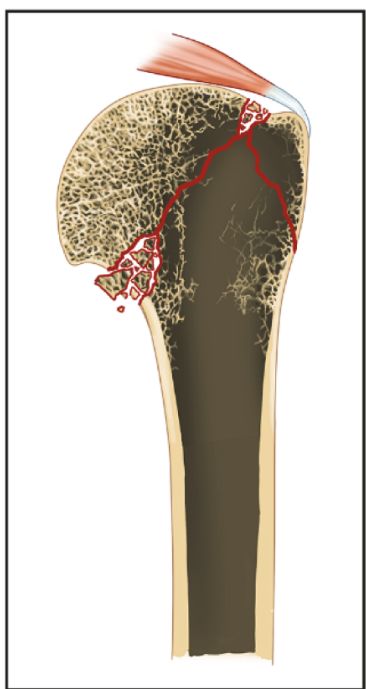

(a)

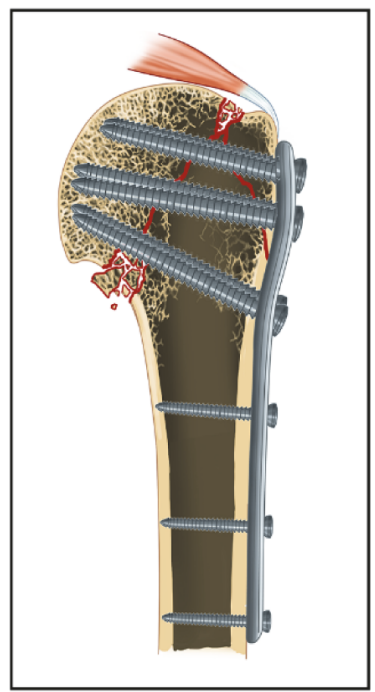

(b)

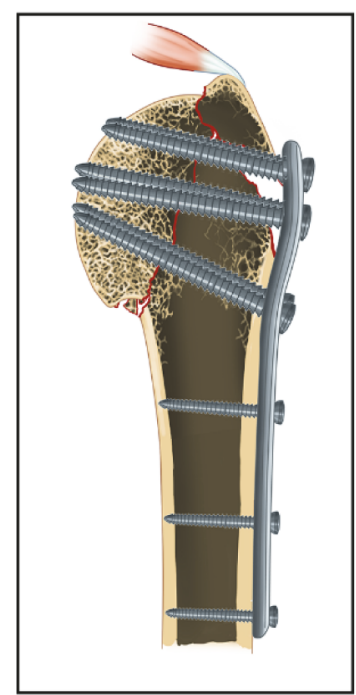

(c)

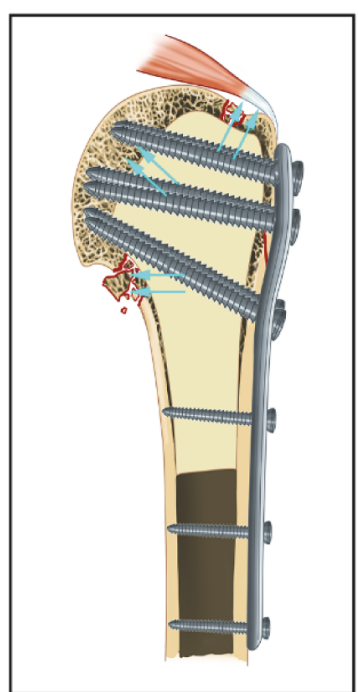

(d)

Figure 5: The schematic diagram of the major effect of fibular allograft (the fracture line marked by red color). (a) The picture presented a coronal plane of elderly osteoporotic PHF. The bone volume in humeral head was nearly empty; (b) the PHF was treated by LCP alone; (c) the retroversion of humeral head, medial, and upward shift of the greater tuberosity, and the humeral head varus occurred due to lack of enough support effect; (d) the PHF was treated by LCP with fibular allograft, and the fibular allograft could provide enough support effect, and the arrows showed the support effect for humeral head, greater tuberosity, and medial cortical bone.

in cases with varus malunion [51]. In addition, a clinical study demonstrated that the place of calcar screws may be cause a high risk of humeral head necrosis [11]. Some investigators tried to use bone cement to strengthen the stability of LCP system in PHF, and the clinical data showed that a good clinical result with a decreasing complication rate [31], but the cement-related heat injuries may exist [34]. The technique of additional medial plate or bone autograft was also attempted to solve the problem of the medial stability, and some drawbacks were existed, such as demanding technique, neurovascular injuries and donor-site morbidity $[32,33,36]$. Our previous study showed that elderly patients with displaced PHF could obtain a satisfied clinical outcome by LCP with fibular allograft [40], the other two clinical studies also presented a similar clinical result as our precious study $[52,53]$. In order to investigate the effect of fibular 
allograft in elderly patients with displaced PHF, we compared the two methods of LCP alone and LCP with fibular allograft, and a better clinical result with a lower complication rate were found in patients treated by LCP with fibular allograft, which was also consistent with the biomechanical data [4144].

A previous study showed that the rate of screw cut-out was up to $43 \%$ in patients order than 60 years [10], so they believed that the bone quality and quantity of the humeral head played a key role in obtaining stable fixation. Xavier et al. thought that cavity defects in proximal humerus were an indication to abandon internal fixation and to choose the method of prosthetic replacement [54]. So recently, hemiarthroplasty has been recommended as a good option for the treatment displaced PHF, especially with elderly patients [55-57]. However, high complication rates and poor functional results have been reported by the method because of tuberosity malreduction or migration, postoperative pain and instability $[58,59]$. In our study, we found that patients treated by LCP alone also had a high complication rate of screw perforation and varus malunion, even if calcar screws were added. We also detected that some patients treated by LCP alone had a problem of shoulder abduction weakness due to the greater tuberosity absorption or migration. The aforementioned problems rarely existed in patients through LCP with fibular allograft in our study. We thought that void filler played a critical role in decreasing the complication rates of screw perforation and varus malunion, and improving the shoulder abduction function, because suitable void filler could provide a satisfied mechanical environment for the head fragment, medial cortical bone and greater tuberosity.

To the best of our knowledge, this is the first comparative study about LCP alone and LCP with fibular allograft in the treatment of elderly displaced PHF. Large amounts of information on the characteristics of patients, treatment outcomes, complications and clinical experience were described in our study. However, there were some limitations in the current study. The number of patients was relatively small and our study was retrospective in nature. Moreover, the operations were performed by three orthopedic experts who maybe have a preference in treatment options, and all the data of patients were collected from a single-center. Therefore, more multicenter prospective randomized controlled trails are needed to overcome these limitations.

In conclusion, the present results showed that that patients treated by LCP with fibular allograft had a better functional outcome and a lower complication rate comparted to patients treated by LCP alone. Suitable void filler in the proximal humerus for supporting the head fragment, medial cortical bone and greater tuberosity might play a key role in reducing the incidence of the complications in elderly patients, especially with osteoporosis.

\section{Data Availability}

Our data used to support the findings of this study are included within the article.

\section{Disclosure}

Hua Chen and Peng Yin are both co-first authors.

\section{Conflicts of Interest}

Each author certifies that he has no commercial associations that might pose a conflict of interest with the submitted article.

\section{Acknowledgments}

This study was supported by the National Natural Science Foundation of China (81401809).

\section{References}

[1] N. Helmy and B. Hintermann, "New trends in the treatment of proximal humerus fractures," Clinical Orthopaedics and Related Research, vol. 442, pp. 100-108, 2006.

[2] C. M. Court-Brown and B. Caesar, "Epidemiology of adult fractures: a review," Injury, vol. 37, no. 8, pp. 691-697, 2006.

[3] M. J. Jo and M. J. Gardner, "Proximal humerus fractures," Current Reviews in Musculoskeletal Medicine, vol. 5, no. 3, pp. 192-198, 2012.

[4] L. Vachtsevanos, L. Hayden, A. S. Desai, and A. Dramis, "Management of proximal humerus fractures in adults," World Journal of Orthopedics, vol. 5, no. 5, pp. 685-693, 2014.

[5] B. Hintermann, H. H. Trouillier, and D. Schafer, "Rigid internal fixation of fractures of the proximal humerus in older patients," The Journal of Bone \& Joint Surgery (British Volume), vol. 82, no. 8, pp. 1107-1112, 2000.

[6] B. Hanson, P. Neidenbach, P. de Boer, and D. Stengel, "Functional outcomes after nonoperative management of fractures of the proximal humerus," Journal of Shoulder and Elbow Surgery, vol. 18, no. 4, pp. 612-621, 2009.

[7] C. Gaebler, M. M. McQueen, and C. M. Court-Brown, "Minimally displaced proximal humeral fractures: Epidemiology and outcome in 507 cases," Acta Orthopaedica, vol. 74, no. 5, pp. 580585, 2003.

[8] J. Agudelo, M. Schürmann, P. Stahel et al., "Analysis of efficacy and failure in proximal humerus fractures treated with locking plates," Journal of Orthopaedic Trauma, vol. 21, no. 10, pp. 676681, 2007.

[9] R. C. Sproul, J. J. Iyengar, Z. Devcic, and B. T. Feeley, "A systematic review of locking plate fixation of proximal humerus fractures," Injury, vol. 42, no. 4, pp. 408-413, 2011.

[10] K. C. Owsley and J. T. Gorczyca, "Fracture displacement and screw cutout after open reduction and locked plate fixation of proximal humeral fractures [corrected]," The Journal of Bone \& Joint Surgery, vol. 90, no. 2, pp. 233-240, 2008.

[11] G. Osterhoff, C. Ossendorf, G. A. Wanner, H.-P. Simmen, and C. M. Werner, "The calcar screw in angular stable plate fixation of proximal humeral fractures - a case study," Journal of Orthopaedic Surgery and Research, vol. 6, no. 1, article no. 50, 2011.

[12] C. N. Cornell, D. Levine, and M. J. Pagnani, "Internal fixation of proximal humerus fractures using the screw-tension band technique," Journal of Orthopaedic Trauma, vol. 8, no. 1, pp. 2327, 1994. 
[13] P. Ellanti and P. Harrington, "Functional outcome after simultaneous bilateral four-part proximal humerus fracture: a comparison of orif and hemiarthroplasty in an individual patient," Case Reports in Orthopedics, vol. 2012, Article ID 941829, 3 pages, 2012.

[14] M. F. Dilisio, R. J. Nowinski, A. M. Hatzidakis, and E. V. Fehringer, "Intramedullary nailing of the proximal humerus: Evolution, technique, and results," Journal of Shoulder and Elbow Surgery, vol. 25, no. 5, pp. e130-e138, 2016.

[15] Y. Zhu, Y. Lu, M. Wang, and C. Jiang, "Treatment of proximal humeral fracture with a proximal humeral nail," Journal of Shoulder and Elbow Surgery, vol. 19, no. 2, pp. 297-302, 2010.

[16] M. Lange, D. Brandt, T. Mittlmeier, and G. Gradl, "Proximal humeral fractures: non-operative treatment versus intramedullary nailing in 2-, 3- and 4-part fractures," Injury, vol. 47, pp. S14-S19, 2016.

[17] N. W. Thompson, S. C. Sloan, A. Adair, and S. N. Simpson, "The limited-contact dynamic compression plate in the management of proximal humeral non-union," Injury, vol. 35, no. 11, pp. 11371139, 2004.

[18] W. Zhang, L. Zeng, Y. Liu et al., “The mechanical benefit of medial support screws in locking plating of proximal humerus fractures," PLoS ONE, vol. 9, no. 8, 2014.

[19] U. Chowdary, H. Prasad, and P. Krishna Subramanyam, "Outcome of locking compression plating for proximal humeral fractures: A prospective study," Journal of Orthopaedic Surgery, vol. 22, no. 1, pp. 4-8, 2014.

[20] D. Aaron, B. O. Parsons, F. Sirveaux, and E. L. Flatow, "Proximal humeral fractures: prosthetic replacement." Instructional Course Lectures, vol. 62, pp. 155-162, 2013.

[21] W. P. Phipatanakul and T. R. Norris, "Indications for prosthetic replacement in proximal humeral fractures.," Instructional Course Lectures, vol. 54, pp. 357-362, 2005.

[22] A. P. Launonen, V. Lepola, T. Flinkkilä, M. Laitinen, M. Paavola, and A. Malmivaara, "Treatment of proximal humerus fractures in the elderly," Acta Orthopaedica, vol. 86, no. 3, pp. 280-285, 2015.

[23] K. Somasundaram, C. P. Huber, V. Babu, and H. Zadeh, "Erratum: Proximal humeral fractures: The role of calcium sulphate augmentation and extended deltoid splitting approach in internal fixation using locking plates (Injury (2013) 44:4 (481487))," Injury, vol. 44, no. 7, p. 1011, 2013.

[24] K. Seide, J. Triebe, M. Faschingbauer et al., "Locked vs. unlocked plate osteosynthesis of the proximal humerus - A biomechanical study," Clinical Biomechanics, vol. 22, no. 2, pp. 176-182, 2007.

[25] S. L. Edwards, N. A. Wilson, L.-Q. Zhang, S. Flores, and B. R. Merk, "Two-part surgical neck fractures of the proximal part of the humerus: A biomechanical evaluation of two fixation techniques," The Journal of Bone \& Joint Surgery, vol. 88, no. 10, pp. 2258-2264, 2006.

[26] H. Chen, X. Ji, Y. Gao et al., "Comparison of intramedullary fibular allograft with locking compression plate versus shoulder hemi-arthroplasty for repair of osteoporotic four-part proximal humerus fracture: Consecutive, prospective, controlled, and comparative study," Orthopaedics \& Traumatology: Surgery \& Research, vol. 102, no. 3, pp. 287-292, 2016.

[27] U. Gönç, M. Atabek, K. Teker, and A. Tanriöver, "Minimally invasive plate osteosynthesis with PHILOS plate for proximal humerus fractures," Acta Orthopaedica et Traumatologica Turcica, vol. 51, no. 1, pp. 17-22, 2017.

[28] M. E. C. Gracitelli, E. A. Malavolta, J. H. Assunção et al., "Locking intramedullary nails compared with locking plates for two- and three-part proximal humeral surgical neck fractures: A randomized controlled trial," Journal of Shoulder and Elbow Surgery, vol. 25, no. 5, pp. 695-703, 2016.

[29] N. Südkamp, J. Bayer, P. Hepp et al., "Open reduction and internal fixation of proximal humeral fractures with use of the locking proximal humerus plate. Results of a prospective, multicenter, observational study," The Journal of Bone \& Joint Surgery, vol. 91, no. 6, pp. 1320-1328, 2009.

[30] M. J. Gardner, Y. Weil, J. U. Barker, B. T. Kelly, D. L. Helfet, and D. G. Lorich, "The importance of medial support in locked plating of proximal humerus fractures," Journal of Orthopaedic Trauma, vol. 21, no. 3, pp. 185-191, 2007.

[31] K. A. Egol, M. T. Sugi, C. C. Ong, N. Montero, R. Davidovitch, and J. D. Zuckerman, "Fracture site augmentation with calcium phosphate cement reduces screw penetration after open reduction-internal fixation of proximal humeral fractures," Journal of Shoulder and Elbow Surgery, vol. 21, no. 6, pp. 741748, 2012.

[32] Y. He, J. He, F. Wang et al., "Application of additional medial plate in treatment of proximal humeral fractures with unstable medial column: A finite element study and clinical practice," Medicine (United States), vol. 94, no. 41, Article ID e1775, 2015.

[33] L. Zhu, Y. Liu, Z. Yang et al., "Locking plate fixation combined with iliac crest bone autologous graft for proximal humerus comminuted fracture," Chinese Medical Journal, vol. 127, no. 9, pp. 1672-1676, 2014.

[34] B. Schliemann, D. Wähnert, C. Theisen et al., "How to enhance the stability of locking plate fixation of proximal humerus fractures? An overview of current biomechanical and clinical data," Injury, vol. 46, no. 7, pp. 1207-1214, 2015.

[35] R. F. Heary, R. P. Schlenk, T. A. Sacchieri et al., "Persistent iliac crest donor site pain: independent outcome assessment," Neurosurgery, vol. 50, no. 3, pp. 510-517, 2002.

[36] J. A. Goulet, L. E. Senunas, G. L. DeSilva, and M. L. V. H. Greenfield, "Autogenous iliac crest bone graft: complications and functional assessment," Clinical Orthopaedics and Related Research, no. 339, pp. 76-81, 1997.

[37] S. Namdari, P. B. Voleti, and S. Mehta, "Evaluation of the osteoporotic proximal humeral fracture and strategies for structural augmentation during surgical treatment," Journal of Shoulder and Elbow Surgery, vol. 21, no. 12, pp. 1787-1795, 2012.

[38] R. Hertel, "Fractures of the proximal humerus in osteoporotic bone," Osteoporosis International, vol. 16, no. 2, pp. S65-S72, 2005.

[39] E. Tan, D. Lie, and M. K. Wong, "Early outcomes of proximal humerus fracture fixation with locking plate and intramedullary fibular strut graft," Orthopedics, vol. 37, no. 9, pp. e822-e827, 2014.

[40] H. Chen, X. Ji, Q. Zhang, X. Liang, and P. Tang, "Clinical outcomes of allograft with locking compression plates for elderly four-part proximal humerus fractures," Journal of Orthopaedic Surgery and Research, vol. 10, no. 1, article no. 114, 2015.

[41] J.-H. Bae, J.-K. Oh, C.-S. Chon, C.-W. Oh, J.-H. Hwang, and Y.-C. Yoon, "The biomechanical performance of locking plate fixation with intramedullary fibular strut graft augmentation in the treatment of unstable fractures of the proximal humerus," The Journal of Bone \& Joint Surgery (British Volume), vol. 93, no. 7, pp. 937-941, 2011.

[42] R. M. Chow, F. Begum, L. A. Beaupre, J. P. Carey, S. Adeeb, and M. J. Bouliane, "Proximal humeral fracture fixation: Locking plate construct \pm intramedullary fibular allograft," Journal of Shoulder and Elbow Surgery, vol. 21, no. 7, pp. 894-901, 2012. 
[43] C. Mathison, R. Chaudhary, L. Beaupre, M. Reynolds, S. Adeeb, and M. Bouliane, "Biomechanical analysis of proximal humeral fixation using locking plate fixation with an intramedullary fibular allograft," Clinical Biomechanics, vol. 25, no. 7, pp. 642646, 2010.

[44] G. Osterhoff, D. Baumgartner, P. Favre et al., "Medial support by fibula bone graft in angular stable plate fixation of proximal humeral fractures: An in vitro study with synthetic bone," Journal of Shoulder and Elbow Surgery, vol. 20, no. 5, pp. 740746, 2011.

[45] C. S. Neer II, "Four-segment classification of proximal humeral fractures: purpose and reliable use," Journal of Shoulder and Elbow Surgery, vol. 11, no. 4, pp. 389-400, 2002.

[46] S. H. Kim, Y. H. Lee, S. W. Chung et al., "Outcomes for four-part proximal humerus fractures treated with a locking compression plate and an autologous iliac bone impaction graft," Injury, vol. 43, no. 10, pp. 1724-1731, 2012.

[47] M. Schnetzke, J. Bockmeyer, F. Porschke, S. Studier-Fischer, P.A. Grützner, and T. Guehring, "Quality of reduction influences outcome after locked-plate fixation of proximal humeral type-C fractures," Journal of Bone and Joint Surgery - American Volume, vol. 98, no. 21, pp. 1777-1785, 2016.

[48] W.-B. Jung, E.-S. Moon, S.-K. Kim, D. Kovacevic, and M.S. Kim, "Does medial support decrease major complications of unstable proximal humerus fractures treated with locking plate?" BMC Musculoskeletal Disorders, vol. 14, article 102, pp. 1-11, 2013.

[49] D. Krappinger, N. Bizzotto, S. Riedmann, C. Kammerlander, C. Hengg, and F. S. Kralinger, "Predicting failure after surgical fixation of proximal humerus fractures," Injury, vol. 42, no. 11, pp. 1283-1288, 2011.

[50] D. Krappinger, T. Roth, M. Gschwentner et al., "Preoperative assessment of the cancellous bone mineral density of the proximal humerus using CT data," Skeletal Radiology, vol. 41, no. 3, pp. 299-304, 2012.

[51] L. Bai, Z. Fu, S. An, P. Zhang, D. Zhang, and B. Jiang, "Effect of calcar screw use in surgical neck fractures of the proximal humerus with unstable medial support: A biomechanical study," Journal of Orthopaedic Trauma, vol. 28, no. 8, pp. 452-457, 2014.

[52] R. M. Hinds, M. R. Garner, W. H. Tran, L. E. Lazaro, J. S. Dines, and D. G. Lorich, "Geriatric proximal humeral fracture patients show similar clinical outcomes to non-geriatric patients after osteosynthesis with endosteal fibular strut allograft augmentation," Journal of Shoulder and Elbow Surgery, vol. 24, no. 6, pp. 889-896, 2015.

[53] A. S. Neviaser, C. M. Hettrich, B. S. Beamer, J. S. Dines, and D. G. Lorich, "Endosteal strut augment reduces complications associated with proximal humeral locking plates," Clinical Orthopaedics and Related Research, vol. 469, no. 12, pp. 33003306, 2011.

[54] X. A. Duralde, E. L. Flatow, R. G. Pollock, G. P. Nicholson, E. B. Self, and L. U. Bigliani, "Operative treatment of nonunions of the surgical neck of the humerus," Journal of Shoulder and Elbow Surgery, vol. 5, no. 3, pp. 169-180, 1996.

[55] P. Valenti, D. Aliani, C. Maroun, J. D. Werthel, and K. Elkolti, "Shoulder hemiarthroplasty for proximal humeral fractures: analysis of clinical and radiographic outcomes at midterm follow-up: a series of 51 patients," European Journal of Orthopaedic Surgery and Traumatology, vol. 27, no. 3, pp. 309315, 2017.

[56] K. Zyto, W. A. Wallace, S. P. Frostick, and B. J. Preston, "Outcome after hemiarthroplasty for three- and four-part fractures of the proximal humerus," Journal of Shoulder and Elbow Surgery, vol. 7, no. 2, pp. 85-89, 1998.

[57] M. Cai, K. Tao, C. Yang, and S. Li, "Internal fixation versus shoulder hemiarthroplasty for displaced 4-part proximal humeral fractures in elderly patients," Orthopedics, vol. 35, no. 9, pp. e1340-e1346, 2012.

[58] S. A. Antuña, J. W. Sperling, and R. H. Cofield, "Shoulder hemiarthroplasty for acute fractures of the proximal humerus: A minimum five-year follow-up," Journal of Shoulder and Elbow Surgery, vol. 17, no. 2, pp. 202-209, 2008.

[59] R. T. Goldman, K. J. Koval, F. Cuomo, M. A. Gallagher, and J. D. Zuckerman, "Functional outcome after humeral head replacement for acute three- and four-part proximal humeral fractures," Journal of Shoulder and Elbow Surgery, vol. 4, no. 2, pp. 81-86, 1995. 


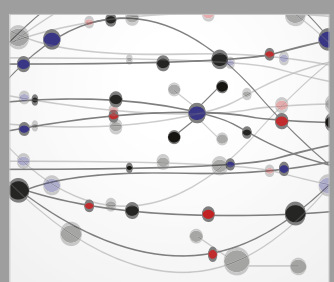

The Scientific World Journal
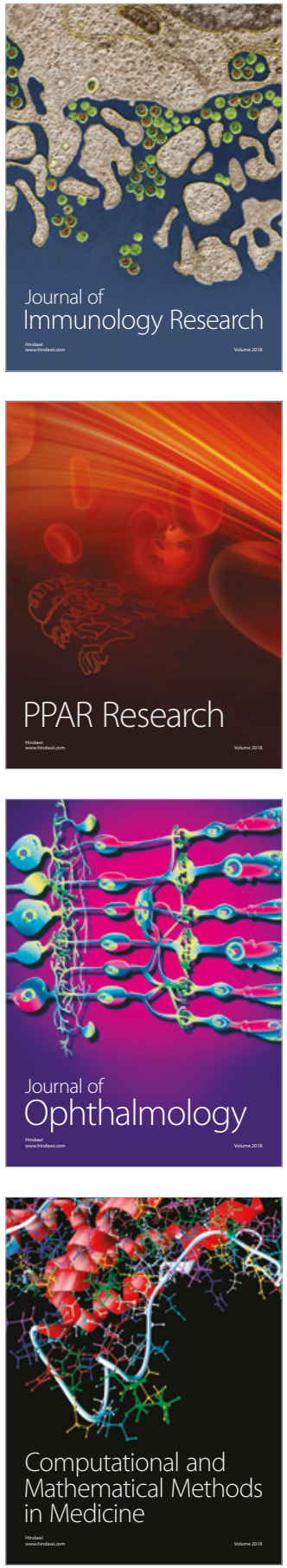

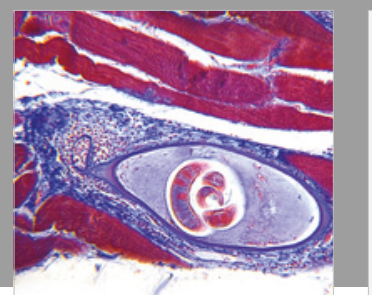

Gastroenterology Research and Practice

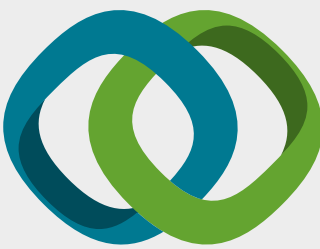

\section{Hindawi}

Submit your manuscripts at

www.hindawi.com
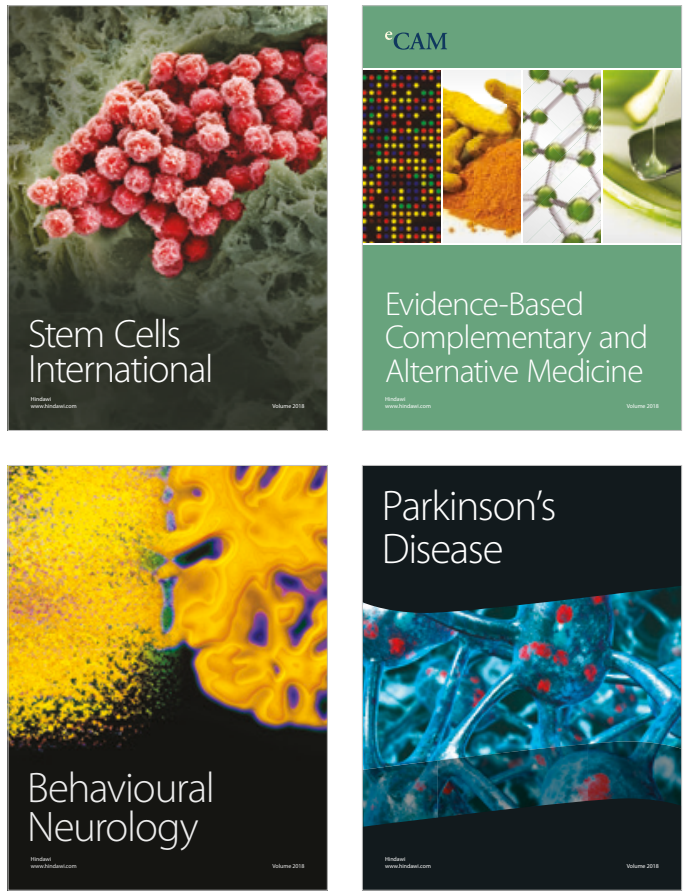

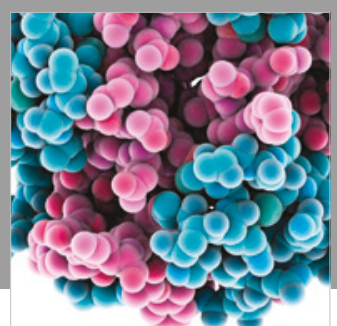

ournal of

Diabetes Research

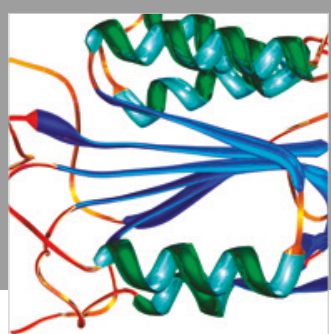

Disease Markers
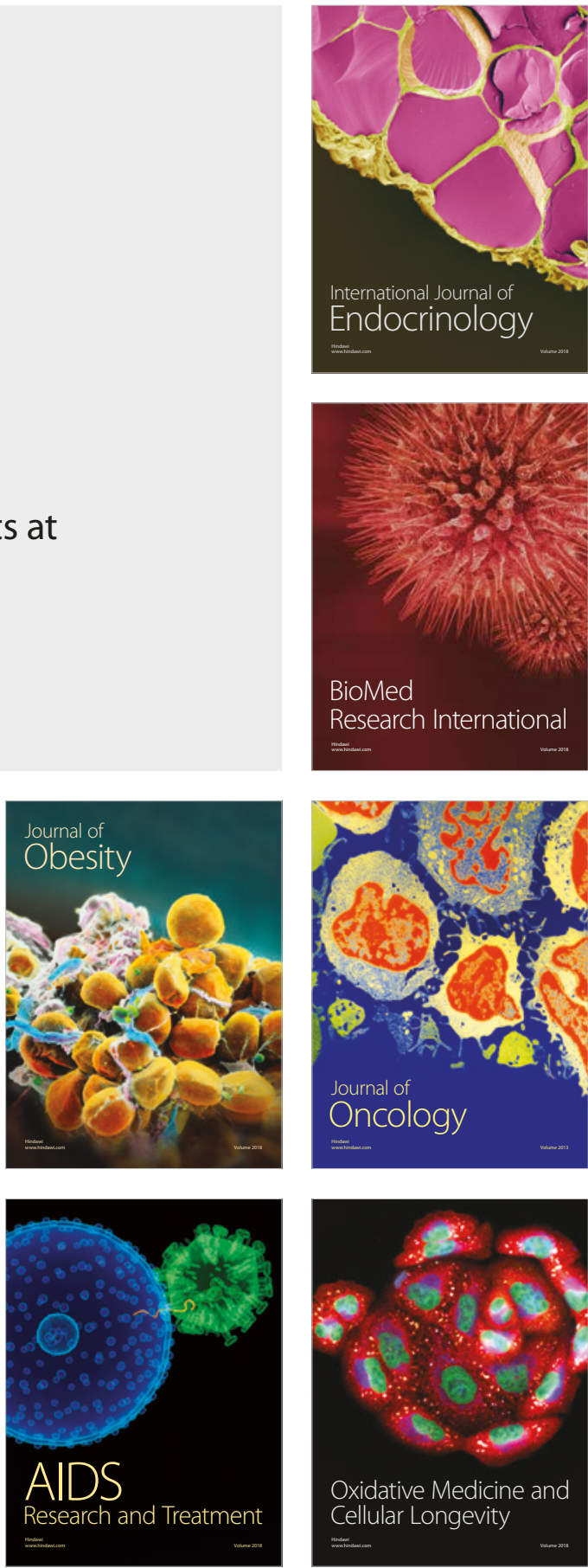